\title{
The role of pulmonary metastasectomy for pulmonary metastasis from head and neck cancer
}

\author{
Satoshi Shiono \\ Department of Thoracic Surgery, Yamagata Prefectural Central Hospital, Yamagata, Japan \\ Correspondence to: Satoshi Shiono. Department of Thoracic Surgery, Yamagata Prefectural Central Hospital, 1800, Oazaaoyagi, Yamagata 990-2292, \\ Japan. Email: sshiono@ypch.gr.jp.
}

\begin{abstract}
The incidence rate of distant metastasis from head and neck $(\mathrm{HN})$ cancers is $4.2-58.8 \%$. The lung is the most common site of distant metastasis, and pulmonary metastasectomy (PM) can be performed in selected patients with pulmonary metastasis originating from $\mathrm{HN}$ cancers. However, due to the small number of study objectives, the knowledge on PM treatment of pulmonary metastasis from HN cancers remains insufficient, and the optimal management of pulmonary metastasis from HN cancer is unclear. Patients with pulmonary metastasis from HN cancer who underwent PM have a better prognosis than those who did not, with reported 5-year overall survival rates after PM of 20.9-59.4\%. A histology of squamous cell carcinoma, incomplete resection, a short disease-free interval (DFI), and the oral cancer have been identified as factors predicting a worse prognosis after PM in this patient population. As a systemic therapy, longer overall survival has been achieved using immune check point inhibitors compared with standard single-agent therapies. Since the clinical and morphological diagnoses of pulmonary metastasis from HN cancers are often difficult, molecular techniques can provide useful information for the differential diagnosis between pulmonary metastasis from HN cancers and primary lung cancers. In cases of suspected pulmonary metastasis from HN cancer, the surgical strategy should be determined based on the patient's clinical background.
\end{abstract}

Keywords: Head and neck cancer (HN cancer); pulmonary metastasis; pulmonary metastasectomy (PM)

Submitted Nov 14, 2019. Accepted for publication Mar 24, 2020.

doi: $10.21037 /$ jtd.2020.04.14

View this article at: http://dx.doi.org/10.21037/jtd.2020.04.14

\section{Introduction}

Despite rapid progress in the field of oncology, metastatic disease remains challenging to treat. Recently, with the advent of treatments for various types of malignancies, the concept of oligometastasis has been proposed (1). Local therapy might be curative for certain patients with distant metastases. Generally, the lung is regarded as the main organ of metastases derived from various malignancies, and pulmonary metastasectomy $(\mathrm{PM})$ is performed in carefully selected patients with pulmonary-limited metastases in clinical practice $(2,3)$. Because there are no randomized studies that have validated the survival benefit of PM, the surgical outcome of PM is controversial (4-6). The advent of systemic therapies could play a significant role in the treatment of pulmonary metastasis.

Criteria for PM were recently proposed by Kondo et al. (7). The major indications for PM are as follows: (I) the patient is a good candidate for surgical intervention; (II) the primary cancer can be controlled; (III) no other extrapulmonary metastases are present, or if present, they can be controlled by surgery or another treatment modality; and (IV) the pulmonary metastasis is considered to be completely resectable. Additional indications include (I) there is an effective systemic chemotherapy as a combined modality; (II) difficulty with the differential diagnosis from primary lung cancer; (III) no other effective treatments available other than resection; and (IV) presence of symptoms due to the pulmonary metastasis, e.g., pneumothorax or hemoptysis (7). 
Table 1 Overall survival of patients with pulmonary metastasis treated with versus without pulmonary metastasectomy since 2008

\begin{tabular}{lcccc}
\hline First author & Publication year & Pulmonary metastasectomy & N & Overall survival \\
\hline Winter $^{\mathrm{a}}(10)$ & 2008 & $(+)$ & 67 & $20.9 \%(5$ years $)$ \\
& & $(-)$ & 67 & $6.0 \%(5$ years $)$ \\
Miyazaki (19) & 2013 & $(+)$ & 24 & $90.0 \%(1$ year) \\
& $(-)$ & 45 & $35.0 \%(1$ year $)$
\end{tabular}

a, patients with versus without pulmonary metastasectomy were compared using matched pair analysis.

\section{Characteristics of pulmonary metastasis from head and neck (HN) cancers}

$\mathrm{HN}$ cancers include mainly oral, pharyngeal, laryngeal, and thyroid cancers. The epidemiology, biological behavior, and treatments differ depending on the anatomical site of the $\mathrm{HN}$ cancer. Therefore, the primary cancer site should be taken into consideration when deciding treatment for $\mathrm{HN}$ cancers (8). The incidence rate of distant metastasis from $\mathrm{HN}$ cancers is $4.2-58.8 \%$ and that of $\mathrm{HN}$ squamous cell carcinoma $1.5-16.8 \%$ (9). Patients with metastasized HN cancers are considered to have an extremely poor prognosis.

According to the site of metastasis from head HN cancers, the lung is the most common (66\%), followed by bone $(22 \%)$ and liver (10\%) (10). A nationwide database study showed that $53.1 \%$ of distant metastases from $\mathrm{HN}$ cancers develop in the lung (11). On the other hand, previous studies on pulmonary metastasis from $\mathrm{HN}$ malignancies had a small number of objectives (10,12-21). Due to the insufficient data, the value of PM for pulmonary metastasis from $\mathrm{HN}$ cancer has not been clarified. The National Comprehensive Cancer Network guidelines, version 2.2019 , which do not specifically address treatment of pulmonary metastasis, proposed the following: surgery, radiotherapy, or systemic therapy with or without radiotherapy is recommended for patients who have only distant metastasis and a performance status of 0 or 1 (8). Therefore, PM may be an optional treatment for select patients with pulmonary metastases (8).

Because the knowledge on PM for pulmonary metastasis from $\mathrm{HN}$ cancers is insufficient and the optimal management of this disease unclear, the aim of this review is to summarize the published studies on, and assess the role of PM for, pulmonary metastasis from $\mathrm{HN}$ cancers.

\section{Outcomes of patients with pulmonary metastasis from HN cancer after PM}

Patients with pulmonary metastasis from $\mathrm{HN}$ cancer who underwent PM have a better prognosis than those who did not. Table 1 shows overall survival data from two studies that compared patients with pulmonary metastasis who underwent PM and those who did not. Although the results should be interpreted cautiously due to selection bias, the patients who underwent PM had a better prognosis $(10,19)$. The median overall survival was 19.4 months for the patients who underwent PM versus only 5.0 months for the patients who did not undergo PM (10).

Previous studies of PM for pulmonary metastasis form HN cancers showed the outcomes after PM. Published studies on the survival and prognostic factors of patients with pulmonary metastasis from HN cancers treated with PM since 1999 are summarized in Table 2. The 5 -year overall survival rate after PM in those studies was 20.9-59.4\% (10,12-21). Regarding the factors predicting a worse prognosis after PM, incomplete resection was associated with poor survival of patients with pulmonary metastasis from $\mathrm{HN}$ cancers $(10,11,17)$, suggesting that complete resection during PM is essential for curative treatment. Some of the studies showed that a short diseasefree interval (DFI) also predicted a worse prognosis in patients with pulmonary metastasis from HN cancers after PM $(11,15,18-21)$; in addition, other studies showed a shorter DFI after PM from other primary sites $(2,3)$. However, as the patients who receive PM are often highly selected patients, it is possible that patients with a shorter DFI were excluded from those studies. Furthermore, patients with slowly growing tumors tend to have longer DFIs, potentially leading to longer survival times, and the 
Table 2 Studies published since 1999 on survival and prognostic factors after pulmonary metastasectomy for pulmonary metastasis from head and neck cancers

\begin{tabular}{|c|c|c|c|c|c|}
\hline First author & Publication year & Study period & $\mathrm{N}$ & 5-year survival & Factors predicting a worse prognosis \\
\hline $\operatorname{Haro}^{\mathrm{a}}(16)$ & 2010 & $1981-2008$ & 25 & $50.0 \%$ & Age $\geq 60$ years, $S q$ (oral cavity, pharynx) \\
\hline Shiono (17) & 2009 & 1980-2006 & 114 & $26.5 \%$ & $\begin{array}{l}\text { Male, Sq, oral cavity cancer, lymph node } \\
\text { metastasis, incomplete resection }\end{array}$ \\
\hline Daiko (18) & 2010 & 1992-2006 & 33 & $43.0 \%$ (3-year survival) & $\mathrm{DFI} \leq 2$ years, Sq, tongue primary \\
\hline
\end{tabular}

${ }^{a}$, this study included thyroid cancer as a primary site. Sq, squamous cell carcinoma; DFI, disease-free interval; NA, not available.

follow-up duration and modalities used for postoperative monitoring are additional factors that influence the DFI. Therefore, the role of the DFI as a prognostic factor might be controversial. The histology of HN cancers can also affect patient survival, with pulmonary metastasis from $\mathrm{HN}$ squamous cell carcinoma considered to predict a worse prognosis (15-18,20,21). Especially, overall survival after PM for pulmonary metastasis from oral floor (17) and tongue $(18,22)$ primary sites were much worse compared with other primary sites. Based on those studies, the indications for PM treatment of pulmonary metastasis from oral floor and tongue cancers might be controversial. Lu et al. showed that the 2-year survival rates after PM for adenoid cystic, thyroid, nasopharyngeal, and $\mathrm{HN}$ squamous cell carcinomas were $100 \%, 88.2 \%, 71.4 \%$, and $59.2 \%$, respectively (23). A study of PM for pulmonary metastasis from adenoid cystic carcinomas reported a 5 -year overall survival rate of $84 \%$ (14). Despite the small number of studies $(n=14)$, the prognosis of resected pulmonary metastasis from adenoid cystic carcinomas might be promising.

In addition to curative resection, DFI, and histology, older age $(11,16,20)$, male sex $(15,17)$, and recurrence before PM $(19,21)$ have been reported as prognostic factors after PM in patients with pulmonary metastasis from $\mathrm{HN}$ cancers. However, those studies were retrospective evaluations of select patient populations, and the patients in those studies had various types of $\mathrm{HN}$ cancers, which have different biological behaviors. Moreover, almost all were single-center studies with long study periods.

\section{Chemotherapy for pulmonary metastasis from HN cancers}

Systemic therapy is recommended for metastatic HN cancers (8). Compared with platinum-based chemotherapy plus fluorouracil alone, cetuximab plus platinum-fluorouracil chemotherapy improved overall survival when given as a first-line treatment to patients with recurrent or metastatic $\mathrm{HN}$ squamous cell carcinoma (24). As HN cancers often express the epidermal growth factor receptor (EGFR), and expression of EGFR is associated with a poor outcome, cetuximab plus platinum-fluorouracil chemotherapy might improve the overall survival of patients with recurrent or metastatic HN squamous cell carcinoma (24).

Nivolumab, which is an anti-programmed death 1 monoclonal antibody, is a promising treatment for advanced diseases, and it resulted in a longer overall survival compared with standard single-agent therapy in patients with recurrent HN carcinoma (25). Using immune checkpoint inhibitors could drastically change the treatment strategy for metastatic HN cancers.

Many clinical trials to study the efficacy of neoadjuvant 
therapy for $\mathrm{HN}$ cancers are ongoing. PD-L1 positivity, high tumor mutation burden, and infiltration of NK cells, CD8, CD26 and Tim 3 positive lymphocytes are considered to be related with response to the treatment (26). Neoadjuvant therapy will become the promising treatment for metastatic HN cancers.

\section{Diagnosis of pulmonary metastasis from HN cancers}

The clinical and morphological diagnoses of pulmonary metastasis from HN cancers are often difficult. If the preoperative radiological diagnosis is lung cancer, a definitive diagnosis of pulmonary metastasis from $\mathrm{HN}$ cancers might not be obtained by pathological evaluation alone. The criteria for diagnosis of pulmonary metastasis from HN cancers used by Winter et al. were a history of advanced-stage $\mathrm{HN}$ cancer, peripheral tumor location, multiple lesions, and a DFI of $<36$ months (10). However, these criteria are considered arbitrary.

Smoking is a common risk factor for laryngeal and lung cancer. The relative risk of lung cancer developing in patients with a history of $\mathrm{HN}$ squamous cell carcinoma is three to six times higher than that in a healthy population (27). In addition, the pathological findings are similar between pulmonary metastasis from $\mathrm{HN}$ cancers and primary squamous cell lung cancer. A reliable method for differential diagnosis of pulmonary metastasis from primary squamous cell carcinoma of lung cancer is being explored.

Ichinose et al. showed the usefulness of a diagnostic algorithm based on immunohistochemical patterns for differentiating between pulmonary metastasis derived from $\mathrm{HN}$ squamous cell carcinoma and primary squamous cell lung cancer (28). Immunochemistry using three types of antibodies (CK19, MMP3, and P13) showed a sensitivity of $96 \%$, specificity of $44 \%$, and accuracy of $65 \%$ for diagnosing pulmonary metastasis, suggesting that immunohistochemistry is a promising diagnostic method (29). Because of the higher prevalence of well-differentiated tumors among $\mathrm{HN}$ squamous cell carcinoma cases, Ichinose et al. suggested that the degree of cell differentiation also helps differentiate HN squamous cell carcinoma from lung squamous cell carcinoma. Geurts et al. differentially diagnosed $\mathrm{HN}$ squamous cell carcinoma from primary lung cancer using a loss of heterozygosity (LOH) analysis (29). In their study, survival after PM for HN squamous cell carcinoma was similar to that after lung resection for metachronous primary squamous cell lung cancer (29).
However, given the cost and time, $\mathrm{LOH}$ analysis is not a realistic approach for differential diagnosis. For molecular diagnosis, sufficient specimens should be obtained preoperatively by needle or transbronchial biopsy. Since pulmonary metastatic lesions tend to be small on computed tomography, it is questionable whether this technique can be put to practical use. More rapid and reliable diagnostic methods are needed in daily clinical practice.

\section{Surgical strategy for pulmonary metastasis from HN cancers}

Due to the difficulty with pathological diagnosis, preoperative definitive diagnosis is challenging. Radiological diagnostic methods can be used to differentiate pulmonary metastases from primary lung cancers, as pulmonary metastases tend to comprise multiple lesions with a round shape and smooth surface; however, not all such lesions have the same characteristics. According to the indications for PM proposed by Kondo et al., PM is warranted for differential diagnosis of primary lung cancers in some cases (7).

A key question is which patients with a history of $\mathrm{HN}$ cancer will benefit from PM. According to previous studies, patients with a DFI >2 years, non-oral cancer, and resectable pulmonary metastasis are good candidates for PM. Because the 5-year overall survival after PM is approximately $30-40 \%, \mathrm{PM}$ is a treatment option for certain patient populations.

In conclusion, pulmonary metastasis from $\mathrm{HN}$ cancers is a common type of metastatic HN cancer. A histology of squamous cell carcinoma, incomplete resection, a short DFI, and the oral cancer have been identified as factors predicting worse survival of patients with pulmonary metastasis from HN cancers. Considering the difficulties associated with preoperative differential diagnosis of pulmonary metastases from primary lung cancers, performing $\mathrm{PM}$ is warranted to determine the diagnosis and achieve complete resection. Novel chemotherapeutic and other treatments for metastatic HN cancers will improve the survival of this patient population.

\section{Acknowledgments}

Funding: None.

\section{Footnote}

Provenance and Peer Review: This article was commissioned 
by the Guest Editor (Khosro Hekmat) for the series "Pulmonary Metastases" published in Fournal of Thoracic Disease. The article has undergone external peer review.

Conflicts of Interest: The author has completed the ICMJE uniform disclosure form (available at http://dx.doi. org/10.21037/jtd.2020.04.14). The series "Pulmonary Metastases" was commissioned by the editorial office without any funding or sponsorship. The author has no other conflicts of interest to declare.

Ethical Statement: The author is accountable for all aspects of the work in ensuring that questions related to the accuracy or integrity of any part of the work are appropriately investigated and resolved.

Open Access Statement: This is an Open Access article distributed in accordance with the Creative Commons Attribution-NonCommercial-NoDerivs 4.0 International License (CC BY-NC-ND 4.0), which permits the noncommercial replication and distribution of the article with the strict proviso that no changes or edits are made and the original work is properly cited (including links to both the formal publication through the relevant DOI and the license). See: https://creativecommons.org/licenses/by-nc-nd/4.0/.

\section{References}

1. Hellman S, Weichselbaum RR. Oligometastases. J Clin Oncol 1995;13:8-10.

2. Pastorino U, Buyse M, Friedel G, et al. Long-term results of lung metastasectomy: prognostic analyses based on 5206 cases. The International Registry of Lung Metastases. J Thorac Cardiovasc Surg 1997;113:37-49.

3. Rena O, Papalia E, Oliaro A, et al. Pulmonary metastases from epithelial tumors: late results of surgical treatment. Eur J Cardiothorac Surg 2006;30:217-22.

4. Treasure T. Pulmonary metastasectomy: a common practice based on weak evidence. Ann R Coll Surg Engl 2007;89:744-8.

5. Treasure T, Milosevic M, Fiorentino F, et al. Pulmonary metastasectomy: what is the practice and where is the evidence for effectiveness? Thorax 2014;69:946-9.

6. Åberg T, Treasure T. Analysis of pulmonary metastasis as an indication for operation: an evidence-based approach. Eur J Cardiothorac Surg 2016;50:792-8.

7. Kondo H, Okumura T, Ohde Y, et al. Surgical treatment for metastatic malignancies. Pulmonary metastasis: indications and outcomes. Int J Clin Oncol 2005;10:81-5.

8. National Comprehensive Cancer Network. NCCN clinical practice guidelines in oncology. Head and neck cancers. Ver 2.2019. Available online: www.nccn.com

9. Ferlito A, Shaha AR, Silver CE, et al. Incidence and sites of distant metastases from head and neck cancer. ORL J Otorhinolaryngol Relat Spec 2001;63:202-7.

10. Winter H, Meimarakis G, Hoffmann G, et al. Does surgical resection of pulmonary metastases of head and neck cancer improve survival? Ann Surg Oncol 2008;15:2915-26.

11. Liu JC, Bhayani M, Kuchta K, et al. Patterns of distant metastasis in head and neck cancer at presentation: Implications for initial evaluation. Oral Oncol 2019;88:131-6.

12. Finley RK, Verazin GT, Driscoll DL, et al. Results of surgical resection of pulmonary metastases of squamous cell carcinoma of the head and neck. Am J Surg 1992;164:594-8.

13. Nibu K, Nakagawa K, Kamata S, et al. Surgical treatment for pulmonary metastases of squamous cell carcinoma of the head and neck. Am J Otolaryngol 1997;18:391-5.

14. Liu D, Labow DM, Dang N, et al. Pulmonary metastasectomy for head and neck cancers. Ann Surg Oncol 1999;6:572-8.

15. Chen F, Sonobe M, Sato K, et al. Pulmonary resection for metastatic head and neck cancer. World J Surg 2008;32:1657-62.

16. Haro A, Yano T, Yoshida T, et al. Results of a surgical resection of pulmonary metastasis from malignant head and neck tumor. Interact Cardiovasc Thorac Surg 2010;10:700-3.

17. Shiono S, Kawamura M, Sato T, et al. Pulmonary metastasectomy for pulmonary metastases of head and neck squamous cell carcinomas. Ann Thorac Surg 2009;88:856-60.

18. Daiko H, Nagai K, Yoshida J, et al. The role of pulmonary resection in tumors metastatic from head and neck carcinomas. Jpn J Clin Oncol 2010;40:639-44.

19. Miyazaki T, Hasegawa $Y$, Hanai N, et al. Survival impact of pulmonary metastasectomy for patients with head and neck cancer. Head Neck 2013;35:1745-51.

20. Yotsukura M, Kinoshita T, Kohno M, et al. Survival predictors after resection of lung metastases of head or neck cancers. Thorac Cancer 2015;6:579-83.

21. Oki T, Hishida T, Yoshida J, et al. Survival and prognostic factors after pulmonary metastasectomy of head and neck cancer: what are the clinically informative prognostic 
factors? Eur J Cardiothorac Surg 2019;55:942-7.

22. Mochizuki T, Okumura S, Ishii G, et al. Surgical resection for oral tongue cancer pulmonary metastases. Interact Cardiovasc Thorac Surg 2010;11:56-9.

23. Lu HJ, Hsieh CC, Yeh CC, et al. Clinical, pathophysiologic and genomic analysis of the outcomes of primary head and neck malignancy after pulmonary metastasectomy. Sci Rep 2019;9:12913.

24. Vermorken JB, Mesia R, Rivera F, et al. Platinum-based chemotherapy plus cetuximab in head and neck cancer. $\mathrm{N}$ Engl J Med 2008;359:1116-27.

25. Ferris RL, Blumenschein G Jr, Fayette J, et al. Nivolumab for recurrent squamous-cell carcinoma of the head and neck. N Engl J Med 2016;375:1856-67.

26. Stafford M, Kaczmar J. The neoadjuvant paradigm

Cite this article as: Shiono $\mathrm{S}$. The role of pulmonary metastasectomy for pulmonary metastasis from head and neck cancer. J Thorac Dis 2021;13(4):2643-2648. doi: 10.21037/ jtd.2020.04.14 reinvigorated: a review of pre-surgical immunotherapy in HNCC. Cancers Head Neck 2020;5:4.

27. Dixit R, Weissfeld JL, Wilson DO, et al. Incidence of head and neck squamous cell carcinoma among subjects at high risk of lung cancer: results from the Pittsburgh Lung Screening Study. Cancer 2015;121:1431-5.

28. Ichinose J, Shinozaki-Ushiku A, Nagayama K, et al. Immunohistochemical pattern analysis of squamous cell carcinoma: lung primary and metastatic tumors of head and neck. Lung Cancer 2016;100:96-101.

29. Geurts TW, Balm AJ, van Velthuysen ML, et al. Survival after surgical resection of pulmonary metastases and second primary squamous cell lung carcinomas in head and neck cancer. Head Neck 2009;31:220-6. 